\title{
Status of market infrastructure in India- A view of Karnataka
}

\author{
NAZATH PARVEEN NAVALUR, BHEEMANAGOUDA O. PATIL, LAXMI N. TIRLAPUR AND \\ K. PRIYANKA
}

Received : 05.02.2015; Revised : 03.08.2015; Accepted : 04.09.2015

\begin{abstract}
Infra-structure is required to ensure free flow of the farm produce and its efficient marketing. Since the technologies on the production front have changed the supply scenario, hence, adequate infrastructure is needed to handle the huge quantity of farm produce. Agricultural sector need efficient functioning of its markets to stimulate economic growth and incomes of the large rural population dependent on agriculture. The efficient markets are important for the stable consumer prices, higher returns to the farmers and reducing post harvest losses. In order to ensure efficient system of trading agricultural markets in almost all the States were established and regulated under the Agriculture Produce Marketing (Development and Regulation) Act. Keeping all these issues in view the study has been undertaken to understand the status of market infrastructure, financial status of regulated markets and the extent of post harvest losses in Karnataka. The study is based purely on secondary data collected from different state Government publications and official websites. The study revealed that the Karnataka's share in agriculture market infrastructure in India is very less and state should increase the investment in infrastructure. The study also reported that the Banglore regulated market has highest annual income, expenditure and profit.
\end{abstract}

KEY WORDS : Market infrastructure, Post harvest losses, Regulated markets

How to cite this paper : Navalur, Nazath Parveen, Patil, Bheemanagouda O., Tirlapur, Laxmi N. and Priyanka, K. (2015). Status of market infrastructure in India- A view of Karnataka. Internat. J. Com. \& Bus. Manage, 8(2) : 162-166. 